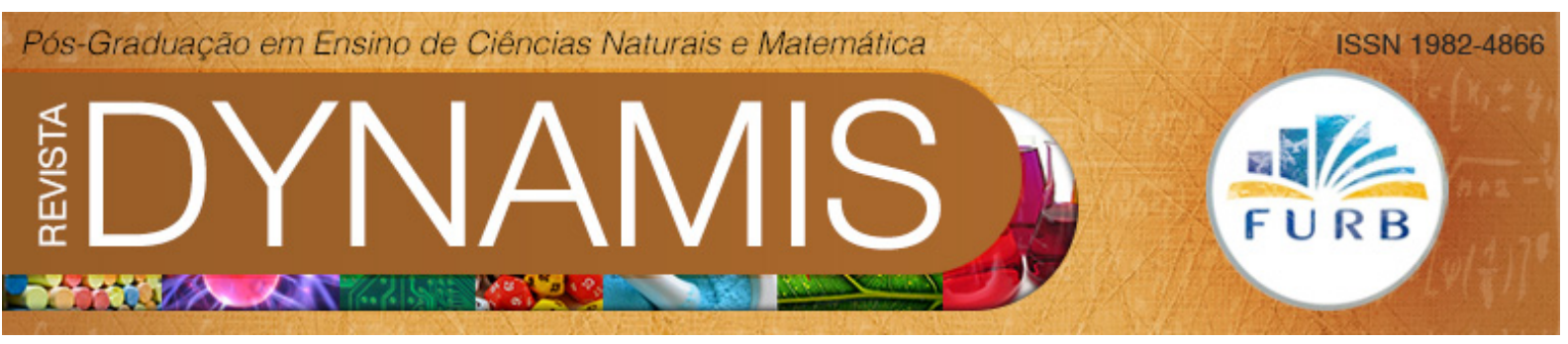

\title{
Petra - da rocha matriz à indústria do petróleo: 0 que é preciso estudar para seguir esse caminho?
}

Petra - the rock matrix to the oil industry: what it takes to go that route study

Laís Feitosa Machado

Universidade Federal do Ceará - UFC

laisfmachado@gmail.com

Vânia Maria Maciel Melo

Universidade Federal do Ceará - UFC

vmmmelo@gmail.com

Artigo recebido em 03/12/2012. Avaliado por pares e publicado em 15/12/2012. 


\section{Resumo}

O projeto Petra tem como principal objetivo desenvolver e/ou despertar vocações de estudantes do ensino médio para carreiras ligadas aos setores de Petróleo \& Gás, Biocombustíveis e Petroquímica. O projeto divide-se em duas etapas principais. A primeira, realizada em 2011, consistiu na realização semanal de aulas teóricas, ministradas por especialistas na temática do petróleo. Ao final do primeiro ano, foi realizado um workshop, quando os estudantes apresentaram trabalhos versando sobre Biocombustíveis, Biocorrosão, Biorremediação, Biossurfactantes e Recuperação Avançada do Petróleo para toda a escola. A segunda parte do projeto teve início em 2012, quando os estudantes iniciaram suas atividades de iniciação científica. Para tanto, grupos de dez alunos participam de aulas práticas em laboratório equipado especialmente para essa finalidade. Os resultados dos projetos serão apresentados em uma Feira de Ciências com o tema "Petróleo \& Gás, Biocombustíveis e Petroquímica", na escola conveniada. Além disso, doze estudantes e três professores que se destacaram na primeira fase do projeto foram selecionados para participaram de um Congresso Nacional, onde terão oportunidade de vivenciar o que vem sendo pesquisado no Brasil e no Mundo nas áreas do projeto. Com base na análise de notas, desenvoltura em laboratório, qualidade dos relatórios e motivação dos participantes conclui-se que o projeto vem contribuindo significativamente para o desempenho intelectual e social dos estudantes e para motivação dos professores. Até o presente momento mais de $40 \%$ dos estudantes participantes do projeto já declararam suas opções por áreas das engenharias, provando que o projeto vem contribuindo para a escolha dessas carreiras.

Palavras chave: Óleo, gás, biocombustíveis, ensino médio, carreiras.

\section{Abstract}

The aim of the Petra project is to develop and/or stimulate vocations of high school students for careers related to the sectors of Oil \& Gas, Biofuels and Petrochemicals. The project is divided into two main parts. The first, held in 2011, consisted in weekly lectures, taught by experts. At the end of the first year, was prepared a workshop on Biofuels, Biocorrosion, Bioremediation, Biosurfactants and Advanced Oil Recovery, where the participants had opportunity to present their proposals for the whole school. The second part of the project began in 2012, when the students started training in research activities. For this purpose, groups of ten students have developed research projects in laboratory. The results of the projects will be presented in a Science Fair with the theme "Oil \& Gas, Petrochemicals and Biofuels", in the associated school. Additionally, twelve students and three teachers who stood out in the first phase of the project were selected to participate in a Brazilian Congress where they will have the opportunity to experience what is being studied in Brazil and the World in areas relating to the project. Based on the grades, skills, fullness, quality of reporting and motivation of the participants we can conclude that the project has contributed significantly to the intellectual and social performance of students and teachers' motivation. To date over $40 \%$ of students participating in the project have already declared their options for areas of engineering, proving that the project has contributed to the choice of these careers.

Key words: Oil, gas, biofuels, high school, careers. 


\section{Introdução}

Desde a sua descoberta, o petróleo tem mobilizado politicamente diversas sociedades. Dentre as várias razões, tem-se o seu alto valor estratégico para a economia dos países e para o desenvolvimento das nações. No cenário mundial, atualmente, o Brasil ocupa uma posição de destaque entre os maiores produtores de petróleo do mundo (PRIOUX; MUXAGATO, 2011). Até isso ocorrer, entretanto, foi preciso que houvesse um grande investimento na capacitação de recursos humanos, injeção de capital e a criação de políticas que priorizassem o petróleo para o desenvolvimento do país. O resultado dessa política permite aos brasileiros comemorar hoje a descoberta do pré-sal.

O termo pré-sal refere-se a um conjunto de rochas, com potencial para geração e acúmulo de petróleo e gás natural, localizado nas porções marinhas do litoral brasileiro. Estas rochas ocorrem em uma faixa de $800 \mathrm{~km}$ de extensão por $200 \mathrm{~km}$ de largura, que vai do litoral de Santa Catarina ao do Espírito Santo, alcançando uma profundidade de até mais de $7.000 \mathrm{~m}$ (LIMA, 2008).

No momento, há uma enorme especulação sobre quantos barris de petróleo pode conter o pré-sal. Alguns acreditam que as reservas devem esconder no mínimo 100 bilhões de barris, o que, segundo a Agência Internacional de Energia, colocaria o Brasil em $6^{\circ}$ lugar entre as maiores reservas de petróleo mundiais. Já outros chegam a afirmar que o pré-sal pode guardar 338 bilhões de barris, o que faria do Brasil o maior detentor de reservas provadas do mundo, superando de longe a Arábia Saudita (LINS, 2008; RODRIGUES, 2008; PRIOUX; MUXAGATO, 2011).

O petróleo é um combustível fóssil, logo, não vai durar para sempre, mas certamente a descoberta do pré-sal foi muito positiva para o Brasil. Além do progresso tecnológico e da movimentação econômica que irá promover, o pré-sal é a maior oportunidade que o Brasil tem de deixar de importar o óleo, o que, teoricamente, reduzirá bastante os preços de seus derivados à população (ADLER, 2009; PETROBRAS, 2009). Somado a tudo isso, ainda há as várias oportunidades de empregos que serão geradas. Os especialistas preveem que até 2020 sejam criados 500.000 empregos diretos e indiretos com a exploração do petróleo no pré-sal (ADLER, 2009).

A exploração dessas novas reservas de petróleo e gás natural exigirão investimentos de centenas de bilhões de dólares e o seu retorno deve chegar a cifras consideravelmente maiores durante muito tempo. Pode estar ali no fundo do mar a fonte de prosperidade das futuras gerações do Brasil (LINS, 2008; RODRIGUES, 2008; PETROBRAS, 2009). Mas, ao mesmo tempo em que confirma o grande potencial das reservas brasileiras, a descoberta do pré-sal nos coloca grandes desafios para sua exploração econômica (PRIOUX; MUXAGATO, 2011).

Além de acusações de aproveitamento político das boas notícias ou do debate acerca da participação estatal, o pré-sal traz a oportunidade de trabalhar e olhar o país em longo prazo. Se muitos participarem das discussões, tanto melhor para o Brasil (LINS, 2008). Assim, é fatídico que investir em educação e em ciências voltadas para o desenvolvimento dos setores de atividades da indústria petrolífera é o combustível certo para acelerar a independência tecnológica do Brasil e melhorar a qualidade de vida dos brasileiros. Para tanto, é necessário investir agora na capacitação de professores e na motivação de estudantes, vislumbrando alavancar carreiras nas áreas de ciências exatas e naturais para suprir a grande demanda técnico-científica que ora se descortina.

Com base nesse contexto e em sintonia com o edital FINEP/MCT/PROMOPETRO/CTPetro 2009/2, foi proposto o projeto: "Petra - Da rocha matriz à indústria do petróleo: O que é preciso estudar para seguir esse caminho?". O projeto 
tem como principal objetivo treinar professores e estimular estudantes do Ensino Médio para as ciências naturais e tecnologias aplicadas aos setores de Petróleo \& Gás, Biocombustíveis e Petroquímica, visando a contribuir para a atualização docente e a despertar vocações para atuação dos estudantes nesses setores de atividades.

\section{Projeto Petra}

O projeto vem sendo desenvolvido na Escola Estadual de Educação Profissional Joaquim Nogueira (EEEPJN), localizada nas proximidades do Campus do Pici da Universidade Federal do Ceará. Participam do projeto quarenta estudantes do Ensino Médio e cinco professores da área de Ciências (01 de biologia, 01 de física, 02 de química e 01 de matemática) da instituição de ensino conveniada. O projeto teve início em 2010 com a divulgação do edital de seleção na EEEPJN, indicando os tipos de avaliações que seriam realizadas no processo de seleção (Conhecimentos Gerais, Português, Lógica, Interpretação de Texto e Redação). Ao todo, 120 alunos participaram da seleção. Destes, trinta foram selecionados como bolsistas ITI-B e dez foram aceitos como voluntários. Todos os professores participantes foram aceitos como bolsistas ATP-A.

O Projeto Petra foi planejado para vigorar no período de dois anos, com suas atividades ocorrendo aos sábados pela manhã com carga horária de 4h/aula semanais, nas dependências do Parque de Desenvolvimento Tecnológico - PADETEC, localizado na Universidade Federal do Ceará. O projeto divide-se em duas partes principais. A primeira delas, realizada durante todo o ano de 2011, consistiu na realização semanal de aulas teóricas e práticas, ministradas por expertises nos assuntos, sobre temas relacionados ao petróleo \& gás, biocombustíveis e petroquímica. Dentro deste eixo, foram ministrados 13 módulos, abordando temáticas distintas, desde "Petróleo e Sociedade" até "Patentes e Propriedade Intelectual". Para cada tema, foi elaborada uma apostila que foi impressa e entregue aos participantes sempre na primeira aula referente a cada módulo (Figura 1).

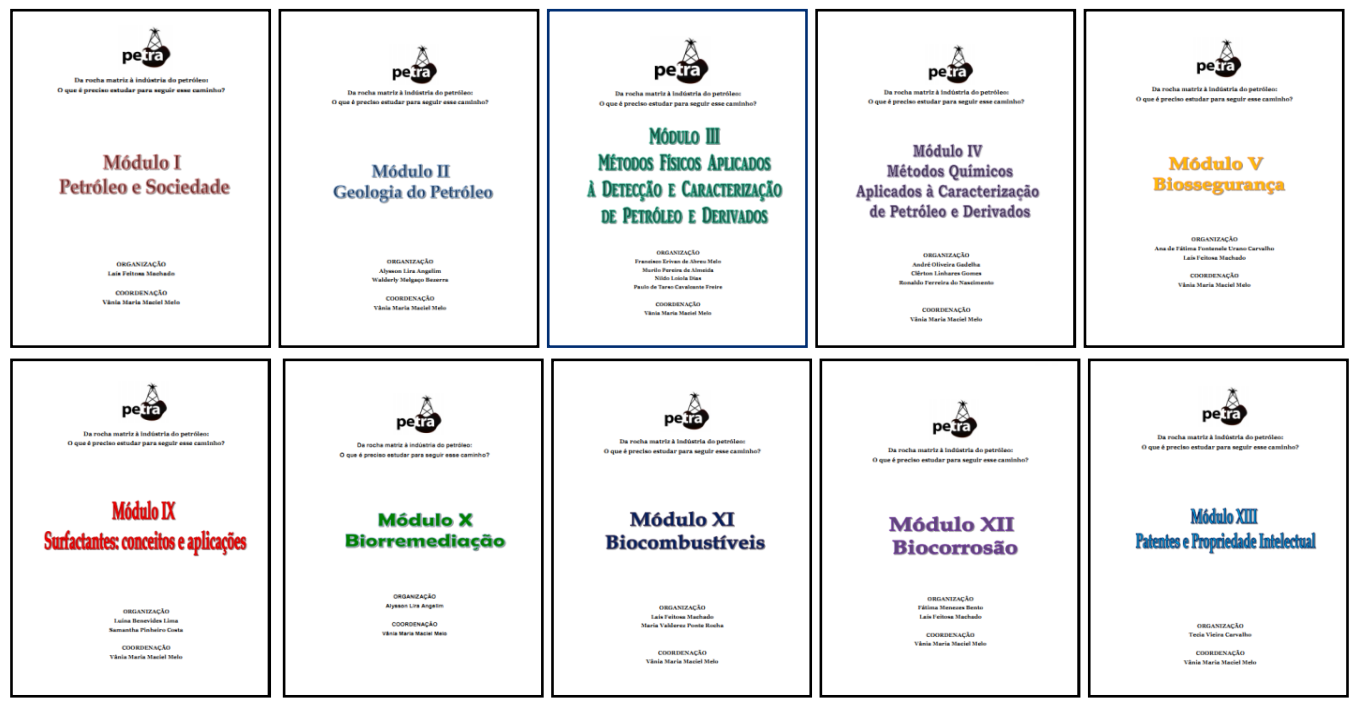

Figura 1 - Módulos ministrados durante o primeiro ano do Projeto Petra. Tabela 1.

Nesta primeira etapa, alunos e professores foram iniciados nos temas apresentados na 
Tabela 1 - Módulos e cargas horárias ministradas durante o primeiro ano do Projeto Petra.

\begin{tabular}{c|l|c} 
Módulo & \multicolumn{1}{|c|}{ Título } & Carga Horária \\
\hline I & Petróleo e Sociedade & $8 \mathrm{~h}$ \\
\hline II & Geologia do Petróleo & $12 \mathrm{~h}$ \\
\hline III & $\begin{array}{l}\text { Métodos físicos aplicados à detecção e caracterização de Petróleo e } \\
\text { derivados }\end{array}$ & $26 \mathrm{~h}$ \\
\hline IV & Métodos químicos aplicados à caracterização de Petróleo e derivados & $24 \mathrm{~h}$ \\
\hline V & Biossegurança & $4 \mathrm{~h}$ \\
\hline VI & Noções de Microbiologia & $8 \mathrm{~h}$ \\
\hline VII & Recuperação Avançada do Petróleo & $4 \mathrm{~h}$ \\
\hline VIII & Microbiologia Aplicada ao Petróleo & $4 \mathrm{~h}$ \\
\hline IX & Surfactantes: Conceito e aplicações & $8 \mathrm{~h}$ \\
\hline X & Biorremediação & $4 \mathrm{~h}$ \\
\hline XI & Biocombustíveis & $4 \mathrm{~h}$ \\
\hline XII & Biocorrosão e biodessulfurização & $4 \mathrm{~h}$ \\
\hline XIII & Inovação tecnológica e propriedade intelectual & $4 \mathrm{~h}$
\end{tabular}

A carga horária de aulas no primeiro ano foi de 122 h/aulas, sendo 80 horas de aulas teóricas (Figura 2) e 22 horas de aulas práticas (Figura 3).

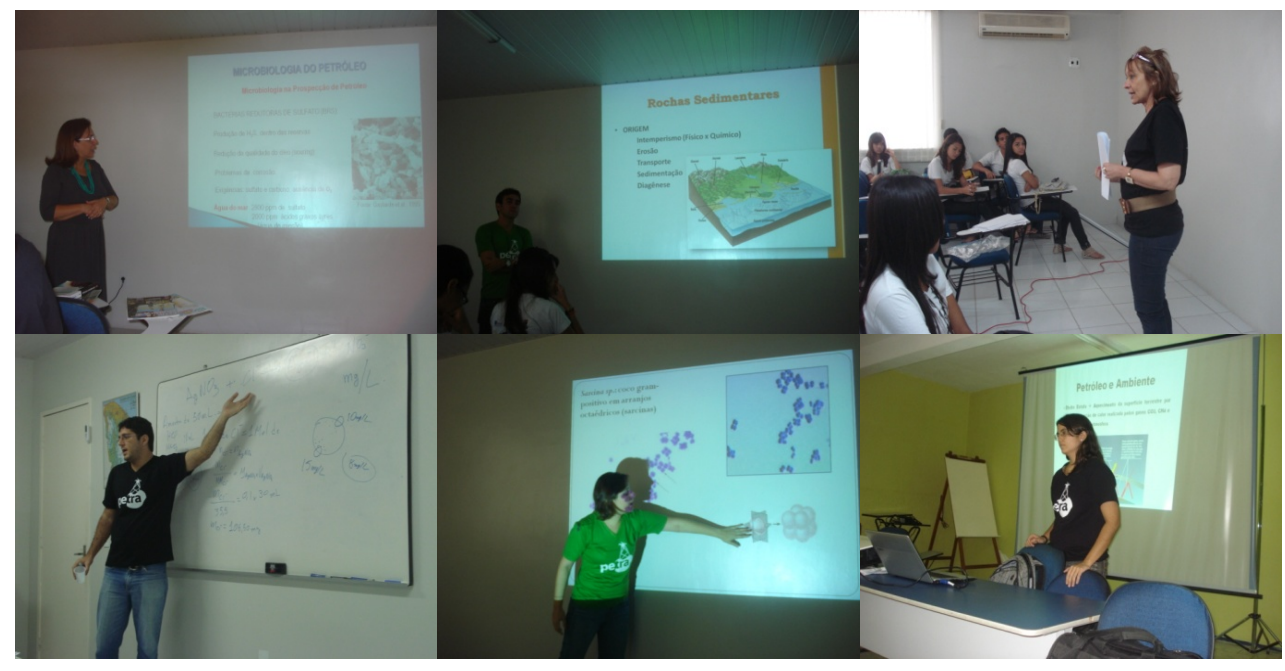

Figura 2 - Aulas teóricas ministradas durante o primeiro ano do Projeto Petra

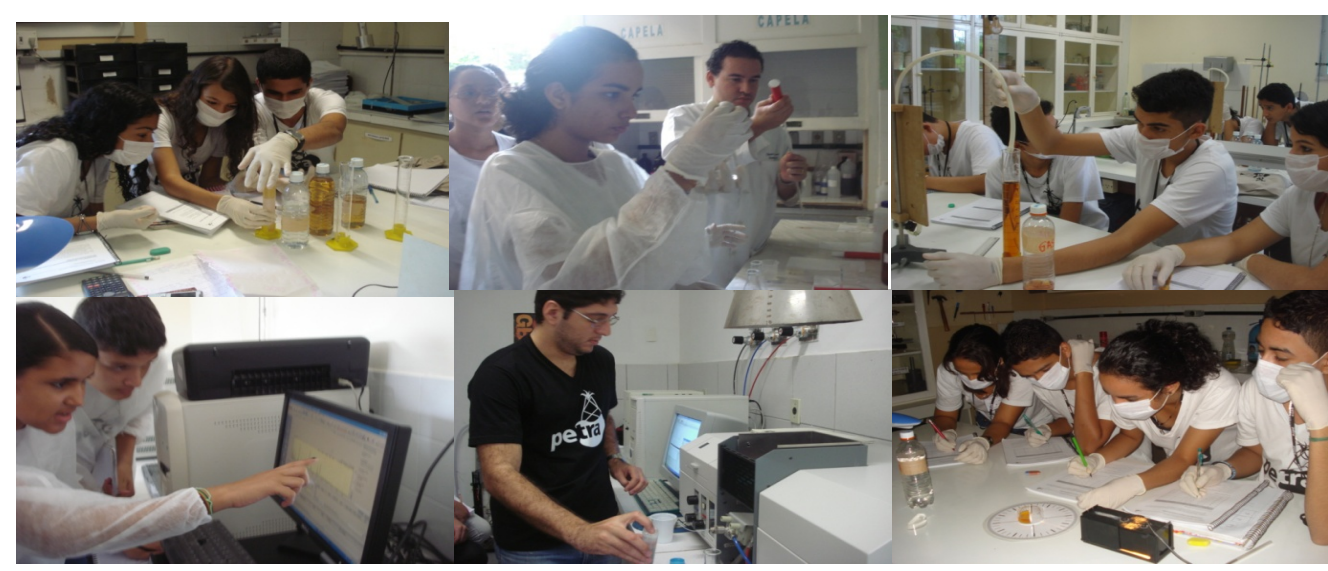

Figura 3 - Aulas práticas ministradas durante o primeiro ano do Projeto Petra

Durante este período, além das aulas teóricas e práticas, foram apresentados e discutidos os documentários "O petróleo tem que ser nosso - Última fronteira” (http://www.apn.org.br), 
"How the Earth was made" (http://www.history.com) e "The Cell" (http:// http://www.bbc.co.uk/). Foi realizado ainda um dia de jogos e atividades lúdicas sobre os conhecimentos transmitidos nos módulos de Biossegurança e de Biocombustíveis, no qual os alunos testaram seus conhecimentos quanto aos temas abordados durante as aulas.

Além disso, dentro do eixo de atividades culturais, o projeto participou do programa "Divulgação e Popularização das Ciências", promovido pelo Centro de Inclusão Tecnológica - CITs do Estado do Ceará. Na ocasião, o projeto foi apresentado para outras escolas do Estado, despertando o interesse de outras instituições para realização do mesmo projeto ou projeto semelhante com seus alunos e professores.

O primeiro ano de projeto foi encerrado com a realização de um Workshop sobre o tema "Petróleo, Gás e Biocombustíveis" na escola conveniada. Nesta ocasião, os estudantes do Petra apresentaram pôsteres sobre os temas Biocombustíveis, Biocorrosão, Biorremediação, Biossurfactantes e Recuperação Avançada do Petróleo para todos os alunos e professores da escola (Figura 4).

Para realização do Workshop, durante o último mês de aulas teóricas, os alunos foram divididos em cinco equipes de oito componentes e, com o auxílio de seus professores e monitores, organizaram material, discutiram os temas dos quais foram encarregados e elaboraram os pôsteres.

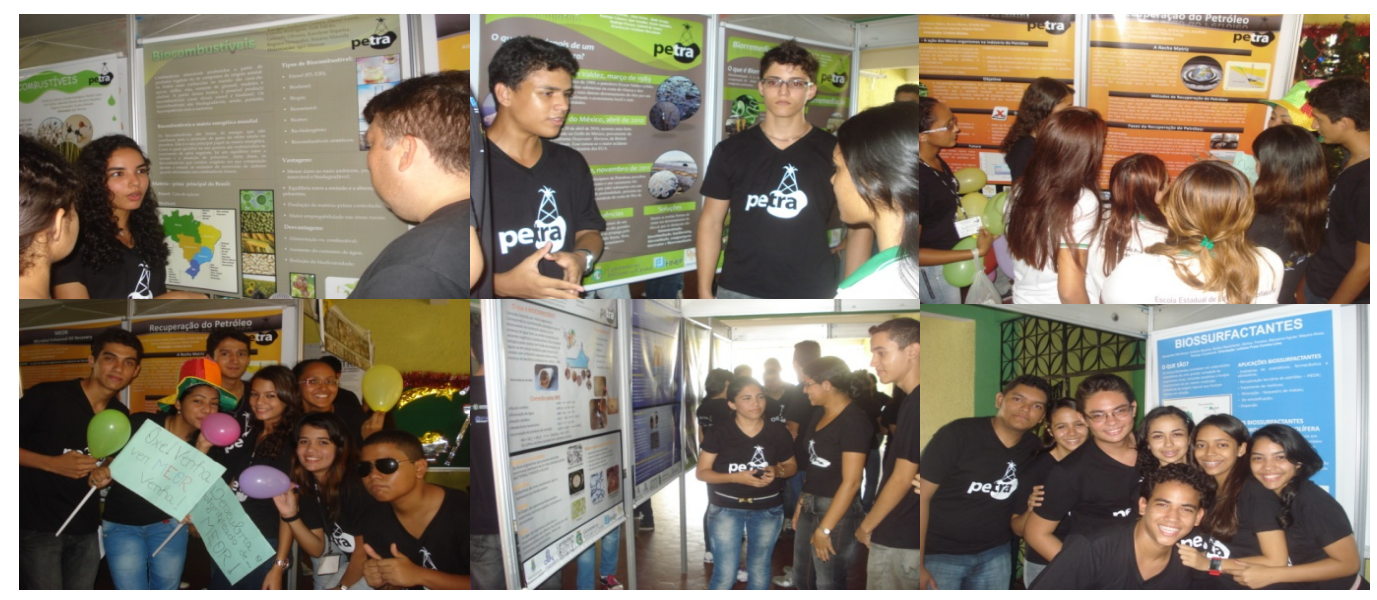

Figura 4 - Workshop "Petróleo, Gás e Biocombustíveis" realizado na escola Escola Estadual Profissionalizante Joaquim Nogueira, encerrando as atividades do primeiro ano do projeto Petra. 


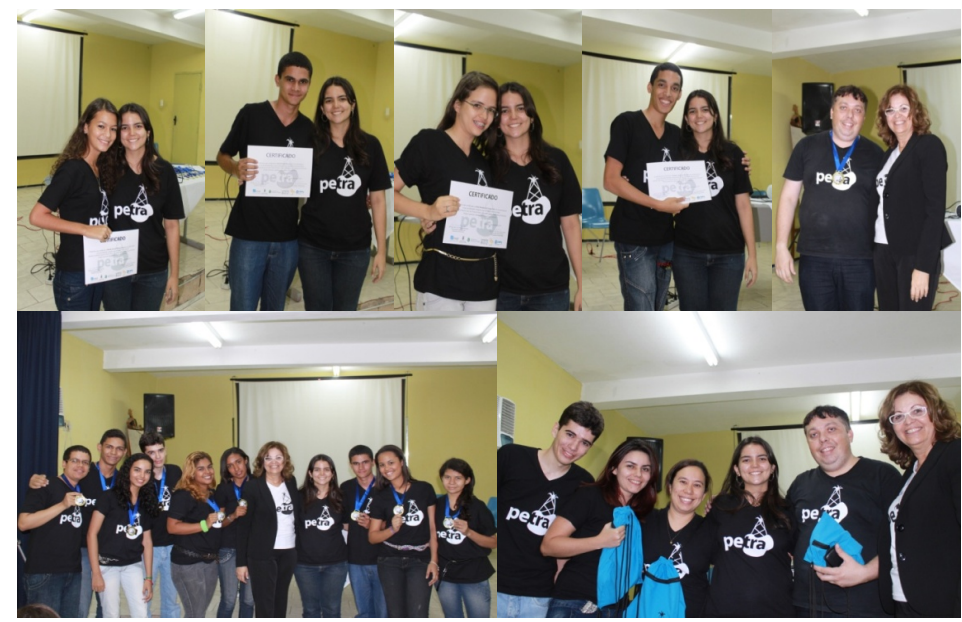

Figura 5 - Premiação dos melhores alunos, equipes e professores no Workshop "Petróleo, Gás e Biocombustíveis".

Ao final do Workshop, foi realizada uma cerimônia de premiação dos estudantes, equipes e professores que se destacaram no primeiro ano do projeto (Figura 5).

Após o Workshop, foi inaugurado, na escola, o Espaço Petra (Figura 6), uma sala destinada às atividades do grupo na instituição, equipada com quatro computadores desktop conectados à internet, um notebook, impressora multifuncional, data show, mesas, cadeiras e armários, além de todo o material de expediente para preparação de trabalhos, consultas, leitura, reuniões e divulgação.

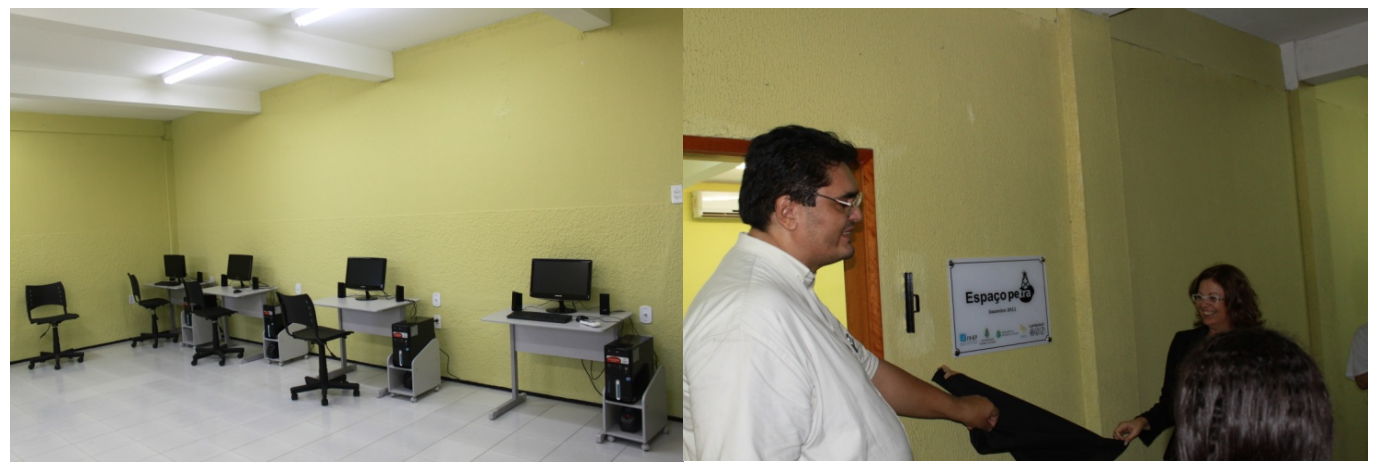

Figura 6 - Inauguração do "Espaço Petra" pelo diretor da Escola Estadual Profissionalizante Joaquim Nogueira e pela Coordenadora do Projeto Petra

Todas as metas previstas para o primeiro ano do projeto foram cumpridas. Os módulos utilizados nas aulas teóricas funcionaram perfeitamente dentro do planejado e as aulas práticas, com rodízios nos laboratórios de física, química e microbiologia, se desenvolveram com êxito.

Os resultados se traduziram no bom desempenho dos alunos, avaliado por relatórios e participação nas atividades guiadas, e no envolvimento dos professores em temas absolutamente novos para todos eles. $\mathrm{O}$ entusiasmo dos participantes foi bastante notório durante o período de aulas, mas, principalmente, quando da realização de atividades lúdicas, da apresentação do projeto em público e da organização e participação no Workshop. A premiação na cerimônia de encerramento provocou enorme euforia nos estudantes, que se mostraram bastante excitados quanto aos seus desempenhos. O entusiasmo ficou ainda maior após a inauguração do Espaço Petra na escola, fato que deixou os estudantes ainda mais animados para o início das atividades do ano seguinte. 
Outra meta concluída foi à reforma do Laboratório de Ciências da EEPJN e a montagem de um laboratório de aulas práticas nas dependências do PADETEC, que será utilizado para o desenvolvimento das atividades da segunda etapa do projeto. Todas essas atividades foram divulgadas na web através do endereço www.lembiotech.ufc.br/petra. Essa página também é utilizada para facilitar a comunicação entre a coordenação do projeto e seus participantes, servindo também como reservatório das informações, das aulas, das atividades e de fotos do dia-a-dia Petra.

A segunda parte do projeto teve início em Fevereiro de 2012 e, nesta etapa, os estudantes iniciaram suas atividades de iniciação científica, desenvolvidas no Laboratório do Petra no PADETEC. Para tanto, mensalmente, cada grupo de dez alunos comparece a uma aula prática relacionada aos temas abordados e discutidos na primeira parte do projeto. As aulas práticas são executadas com materiais simples, facilmente encontrados em laboratórios escolares, e apresentam roteiros exequíveis para $\mathrm{o}$ ensino das ciências aplicadas à biogeoquímica do petróleo nas escolas.

No segundo semestre de 2012, os doze melhores alunos, avaliados por atividades, provas e interesse, e três professores irão participar do XIX Congresso Brasileiro de Engenharia Química, a ser realizado em Búzios, no estado do Rio de Janeiro. Nesta ocasião, os participantes terão oportunidade de vivenciar as experiências proporcionadas por um congresso, participando de sessões de pôsteres e de exposições e assistindo a palestras e a mesas redondas ministradas e compostas por profissionais experientes na área de Engenharia Química, principalmente nas áreas de Energia, Petróleo, Gás e Biocombustíveis.

Para finalização do projeto, ao final do ano, será realizada na escola uma Feira de Ciências com o tema "Petróleo \& Gás, Biocombustíveis e Petroquímica", na qual os alunos terão oportunidade de apresentar os resultados de seus projetos de pesquisa para toda a escola.

\section{Considerações Finais}

Com base na análise do desempenho dos alunos, participação em seminários, produção de pôsteres, desenvoltura em laboratório e qualidade dos relatórios, é possível concluir que o desenvolvimento do projeto vem contribuindo positiva e significativamente para o crescimento intelectual e social dos estudantes e motivação dos professores. O projeto tem contribuído ainda para o amadurecimento dos participantes, que têm tido oportunidade de estudar com especialistas de alto nível e de conhecer laboratórios e equipamentos utilizados em pesquisas de ponta na Universidade.

A evolução de estudantes e professores é notória, assim como a motivação para participar de todas as atividades. E, ao longo de um ano e meio de projeto, já é possível perceber nos alunos o despertar de aptidões para áreas de engenharia, geologia e biologia, temas relacionados à temática Petróleo \& Gás, Biocombustíveis e Petroquímica.

Assim, antes mesmo de concluído, pode-se dizer que o Projeto Petra contribuiu sobremaneira para o crescimento dos seus participantes, promovendo o desenvolvimento de habilidades e competências importantíssimas para sua atuação como cidadãos e/ou profissionais.

\section{Referências}

ADLER, P. Pré-sal brasileiro: petróleo, riqueza e empregos. 2009. In: Guia da Carreira. Disponível em: <http://www.guiadacarreira.com.br/artigos/atualidades/pre-salbrasileiro/>. Acesso: 02 jul 2012. 
LIMA, P.C.R. Os desafios, os impactos e a gestão da exploração do pré-sal. Biblioteca Digital da Câmara dos Deputados. Consultoria Legislativa. 2008.

LINS, M.A. del T. Petróleo do pré-sal: as dificuldades de lidar com a bonança. Brasileiros, v.17, n.17, 2008.

PETROBRÁ/Pré-sal. 2009. Disponível em <http://www2.petrobras.com.br/presal/10perguntas/>. Acesso em 15 ago. 2010.

PRIOUX, B.L.; MUXAGATO, B. A descoberta das jazidas do pré-sal: um desafio para o futuro da energia no Brasil. Intellector, v.8, n.15, p.1-33, 2011.

RODRIGUES, M.N. Entenda o que é a camada pré-sal. Brasil de fato - uma visão do Brasil e do mundo. Edição de 23 de Setembro de 2008. 